\title{
Reflections on Critical Thinking in the Nursing Process and Japanese Nurse Education
}

\author{
Misae Ito ${ }^{1}$, Kyoko Murakami ${ }^{1}$, Satoko Ono ${ }^{2}$, Margaret McMillan ${ }^{3}$ \\ ${ }^{1}$ Faculty of Health Sciences, Yamaguchi University Graduate School of Medicine, Ube, Japan \\ ${ }^{2}$ Doctoral Program, Yamaguchi University Graduate School of Medicine, Ube, Japan \\ ${ }^{3}$ School of Nursing and Midwifery, University of Newcastle, Australia
}

This reflective paper examines nurse education in Japan in the context of a rapidly changing and increasingly complex health care environment. The purpose of this paper is to i) provide an overview of Japanese changing nursing discipline ii) make an appraisal of whether the core elements of the Nursing Process are sufficient to ensure optimal nursing responses to person-centered care, iii) examine issues around the management of change that need further exploration if nurses in Japan are to continue to have a central role in responding to consumer/patient needs. Following an overview of the current nurse education system and supporting nursing organizations we critically examine the existing curriculum and models of practice including the nursing process in the light of the need for practice-ready reflective nurses.

Keywords: Curriculum; Nurse education; Nursing process; Critical thinking; Educational reform

\section{INTRODUCTION}

Ideas about professional education and practice change over time. Paradigm shifts take time, but new ideas are tested and expanded upon even if regulation and policies remain static. Responses to changing patterns of disease and advances in the technology impacting education and practice lead to inevitable change. Leadership for innovation is essential but personal and professional styles influence the reception of ideas for change.

Nursing education in Japan has historically emphasized the development of nurses with the ability to work immediately after graduation through the acquisition of specialized knowledge and skills. Today, with advanced medical technology and the diversity of consumer values in Japan paralleling those in western countries, nurses are required to acquire knowledge that can be applied in diverse health sedttings and to be able to make accurate clinical judgments irrespective of the context of practice (Alfaro-LeFevre, 2010; Herdman \& Kamitsuru, 2017). Critical thinking ability is highlighted as a key element of competence for skill development for evidence-based practice and learning to grow as a nurse and to undertake research. The 'critical' element is at the core of the stronger focus on thinking skills and attitudes that support the nursing process and nursing practice (Kusumi, 2015).

Critical thinking is defined as "...reflective and reasonable thinking that is focused on deciding what to believe or do (Eniss, 1985)." Critical tinkling is a complex process in any circumstance and there are no right definitions (Alfalo-Lefevre, 2017). The standards of the American Nurses Association (ANA, 2015) describe a competent level of nursing care within the nursing process as demonstrative of critical thinking model. The nursing process includes the components of assessment, diagnosis, outcomes identification, planning, implementation, and evaluation. The ability to think 'critically', collect information from multiple viewpoints,

\section{Review Article}

pISSN 2288-8675 · elSSN 2508-9145

J Probl Based Learn 2021;8(1):41-50

https://doi.org/10.24313/jpbl.2020.00318

Received: December 18, 2021

Revised: February 24, 2021

Accepted: March 05, 2021

Corresponding author:

Misae Ito,

Faculty of Health Sciences,

Yamaguchi University Graduate

School of Medicine 1-1-1 Minami-

Kogushi, Ube, Yamaguchi 755-8505,

JAPAN

E-mail m-ito@yamaguchi-u.ac.jp

Tel: +81-836-22-2821

Fax: +81-836-21-2130

(C) Copyright 2021 International Society for Problem-Based Learning

(c) This is an Open Access article distributed under the terms of the Creative Commons Attribution Non-Commercial License (http://creativecommons.org/licenses/ by-nc/4.0/) which permits unrestricted non-commercial use, distribution, and reproduction in any medium, provided the original work is properly cited. 
and make judgments, seems to be a fundamental skill that is essential to nursing practice as represented by evidence-based nursing (EBN), learning and research processes that nurses need to develop (Alfaro-LeFevre, 2010; Herdman \& Kamitsuru, 2017; Ogata, 2016). However, it can be difficult for nurses to engage in critical thinking in their busy daily practice. Besides, as nurse educators, we sometimes feel some personal resistance to innovation when students demonstrate critical thinking in nursing education because in the Japanese context this could be seen as a barrier to 'respecting harmony (Tsujimura, et al., 2016; Turale, Ito, Murakami, \& Nakao, 2009).'

In this paper, we discuss the context of nurse education in Japan before discussing the nursing process model and its applicability in the contemporary clinical environment. This paper also discusses how important the ability to think critically when difficult nursing clinical judgement is needed and provides a perspective for solution-oriented strategies when routines are disrupted.

\section{PURPOSE}

The purpose of this paper is to i) provide an overview of Japan's changing nursing discipline ii) make an appraisal of whether the core elements of the Nursing Process are sufficient to ensure optimal nursing responses to person-centered care, iii) examine issues around the management of change that need further exploration if nurses in Japan are to continue to have a central role in responding to consumer/patient needs.

\section{FACTORS AFFECTING DEVELOPMENT OF CRITICAL THINKING IN NURSING EDUCATION}

\section{Background and policy}

A major driver of policy change in nurse education and the qualifications framework has been Japan's rapidly aging population (Primomo, 2000); the resulting increasing complexity in clinical care has led to an expansion in the scope of practice and increased emphasis on ongoing professional education (Japanese Nursing Association, 2016a; 2015). The aging population has also meant a move towards community-based care. The demands for high levels of medical and nursing care are increasing in line with other countries in southeast Asia (Nurjono, et al., 2020). Professional health services are also becoming more diversified and complex. These changes have occurred as a result of the country's declining birth rate as well as a response to the 'super-aging' population, the increasing sophistication of medical care and changes in public awareness about health services.
Japan is moving towards a more community-based treatment model. The various policies and systems related to treatment and rehabilitation developed by the Ministry of Health, Labour and Welfare (MHLW) are rapidly shifting from the traditional hospital-based to a community-based system: in Japan this is referred to as establishing "the Community-based Integrated Care system" (Ministry of Health, Labour and Welfare, 2016). The number of people aged over 75 has increased along with an increase in those with dementia. The comprehensive support and service provision systems in local communities enable people to continue living their own lives in their familiar communities as much as possible until the end of their lives. It has become essential for health and welfare service providers, including nurses, to support people living in the community from a person-centered perspective. Given these catalysts for change, the expectations for renewal placed on the nursing profession are high. Japanese nursing education used to have as its foundation nursing care in the hospital but now nursing care at home is becoming more and more a part of practice. Therefore education also needs to include more community-based perspectives involving persons with dementia in community. These medical and nursing systems in community set a unique example for the world. Now more than ever, nurses need to be able to make accurate clinical judgments irrespective of the context of practice (Alfaro-LeFevre, 2010; Herdman \& Kamitsuru, 2017) to respond to changing consumer situations.

\section{The role of nursing associations in Japan}

Many professional nursing bodies in Japan are dedicated to the development of nursing as a discipline, quality of nurse education, and nursing care. These have a role in setting the nurse education agenda and standards of nursing practice. There are 46 nursing societies within the Japan Association of Nursing Academies (JANA) such as the Japan Academy of Nursing Science and Japan Society of Nursing Research, which serves to encourage collaboration between societies, contribute to nursing development, and disseminate position statements to the society and nationally. Japanese academics promote the development of nursing science and nurture young scientists through these nursing societies. The Japan Association of Nursing Academies has responded to the Ministry of Health, Labour, and Welfare's policy with a statement on changes in health care, childrearing, and long-term care, health, and welfare services from their professional standpoints.

The Japanese Nursing Association is the largest nursing organization in Japan, shapes the future of nursing in Japan and has as its mission the improvement of standards of professional nursing working conditions for nurses as well as developing nursing ex- 
pertise (Japanese Nursing Association, 2015). This is detailed in the Japanese Nursing Association publication "The future vision of nursing: Nurses' endeavor towards 2025" outlining its mission for the reconstruction of health, medical and welfare systems. Many Japanese organizations including the Ministry of Education, Culture, Sports, Science and Technology (MEXT); Ministry of Health, Labour and Welfare; and the Japanese Nursing Association emphasize lifelong learning for nurses.

\section{Preparation for nursing practice in Japan}

Longstanding concerns about the educational level and status of Japanese nurses have come from within and outside the country (Long, 1984): educational programs were considered to "lack theory, focus on a pragmatic rather than a critical approach to nursing practice, be primarily taught by physicians due to the shortage of qualified nursing faculty and be short (Primomo, 2000)." It is important to acknowledge that ideology and culture will have an impact on the nature and extent of change in any context of practice or education (McMillan \& Little, 2019).

There are three routes to becoming a registered nurse in Japan. These include a three-year diploma course; a three-year college course leading to an Associate of Science in Nursing (ASN) or a four-year university-based Bachelor of Science in Nursing (BSN) program. Graduates of courses have to take national examinations to qualify to apply for a nursing license. There are three main classifications of nurses: public health nurses, midwives, nurses (including assistant nurses) (Japanese Nursing Association, 2016a). The standards for nurse education are the same for all these options based on principles established for college/university and prescribed in legislation. The Ministry of Education, Culture, Sports, Science, and Technology regulates baccalaureate and higher degree programs, licenses the schools, and determines the curriculum (Primomo, 2000). Other directives come from Specified Rules of Schools and Vocational Schools for public health nurses, midwives, and registered nurses from the Ministry of Health, Labour, and Welfare. Given the complex nature of the regulatory frameworks, some nurse educators involved in course design, development, and implementation have concluded that there is little room for manoeuvre in the saturated curriculum (Ishibashi, et al., 2017a).

In response to projections for the increases in demand for qualified nurses, the number of nursing schools has increased rapidly and, in 2019, Japan numbered 1,085 nursing schools (Ministry of Education, Culture, Sports, Science and Technology, 2019). Training schools outnumber university faculties by 2.4 times and enrol the largest number of students (Figure 1). As a result of this growth, there is a shortage of a new generation of qualified nursing faculty. The Japan Association of Nursing Programs in Universities (2020) report provides a profile on 65-year faculty members in 2018: $0.3 \%$ at national universities, $1.7 \%$ at public universities, and $8.3 \%$ at private universities. Private universities have a lower percentage of faculties in their 30s than national or public universities. Many senior nursing academics have also retired from government universities at the designated retirement age of 65 and some continue to work in private universities where there is less regulation regarding age. The implications of the rapid increase in schools are not yet apparent but shortages of doctoral-prepared nurse educators (Japan Association of Nursing Programs in Universities, 2020), and high workloads and lack of culturally appropriate nursing models have long been noted as problematic (Turale, Ito, Murakami, \& Nakao, 2009). The first doctoral nursing program in Japan began in 1966, and the number of schools and graduates is increasing. According to the 2018 Fact-finding at Japan Association of Nursing Programs in Universities (the Japan Association of Nursing Programs in Universities, 2020), approximately one third (34.2\%) of faculty members of nursing programs in universities had obtained a doctorate. Most nursing doctoral students acknowledge the consistency between curriculum developments and the goals within the university's philosophy and mission (Miki, Gregg, Arimoto, Nagata, and Murashima, 2012). There are challenges within faculties given the limitations in infrastructure supporting a doctoral program, such as funding sources and available human resources (Arimoto, Gregg, Nagata, Miki, \& Murashima, 2012).

\section{THENURSING CURRICULUMINJAPAN}

There is a range of nurse education courses in Japan all of which prepare students to take the national examination required for registration. The national examination ensures the minimum competencies for nurses to provide safe and quality care, but nursing competencies are complex. While the national examination tests knowledge and some attitudinal qualities, it does not assess clinical skills or arguably critical thinking or all the required competencies. In a Canadian context, the view is that teaching to a test and creating a curriculum around a specific examination is counterintuitive and not consistent with sound principles of curriculum development (McGillis Hall, Lalonde, Kashin, Yoo \& Moran, 2018).

University and college faculty construct their curriculum implementation plans relying on a model within a curriculum that includes the core educational content for BSN programs in all nursing faculties in universities and colleges. The learning objectives to be utilized are prescribed when the curriculum plan is 


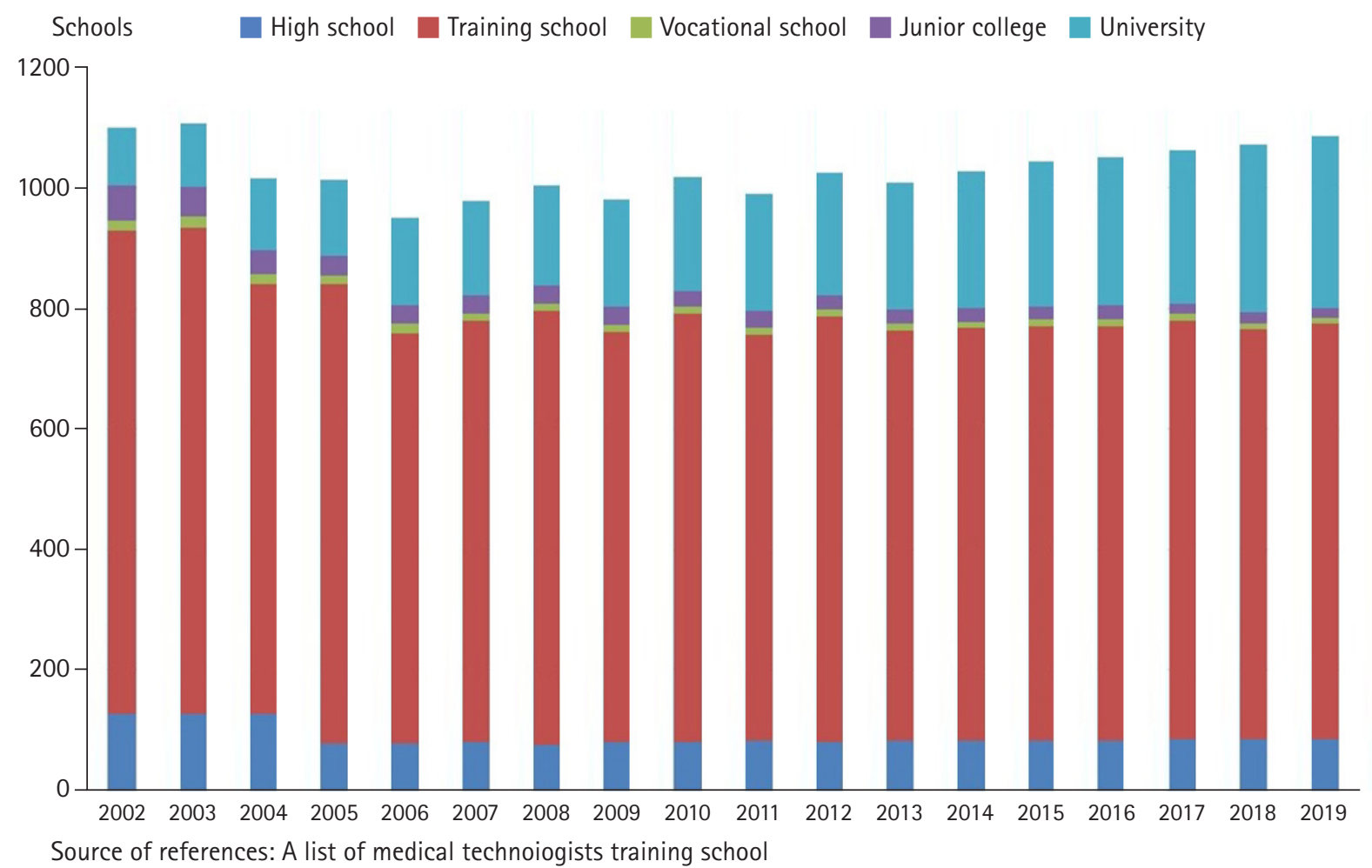

Figure 1. List of nurses training schools by year in Japan Retrieved October 1, 2020, from https://www.mext.go.jp/content/20200417-mxt_ igaku-100001205_21.pdf

created (Committee for Fostering Human Resources in Nursing Education, Ministry of Education, Culture, Sports, Science and Technology, 2017) to respond a social change and contribute to assure quality of nursing bachelor degree program. The learning objectives mainly consist of the following categories - society and nursing, basic knowledge for comprehending nursing objects, professional basic knowledge for nursing practice, essential basic knowledge for nursing practice in various situations, clinical practice, and nursing research. The list provides evidence that content within curricula is covered and thus ensures the Japanese graduate can confidently and competently carry out the contemporary role of the Registered Nurse in that country. There are prescribed competencies that students are expected to have achieved at graduation. These statements about graduate abilities are similar in some ways to those expressed by many schools of nursing: professionalism, nursing knowledge and practice, ability to respond to issues based on evidence, communication, collaboration in health, medicine and welfare, management of quality and safety, scientific investigation, commitment to lifelong learning, an ability to assume an expanding role as required by society (Ishibashi, et al., 2017b; Okura \& Takizawa, 2018).

\section{COMPARISONS IN EDUCATION PRACTICES}

The subject-based nursing curricula in Japan contrasts to the concept-based curricula in most Western universities and the delivery model has been predominantly face to face. The complexity of health care worldwide requires nursing graduates to use effective thinking skills and many nursing programs are revising curricula to a concept-based model that encourages problem-solving, effective thinking, and the transferability of knowledge (Baron, 2017). Subject-based curricula usually require students to memorize a great deal of knowledge that is required for a short time and there is limited time for them to develop critical thinking and clinical reasoning skills (Baron, 2017). Nurse educators in Japan need to make a major shift in their teaching philosophy and teaching style to promote problem-solving and critical thinking.

A 2003 report (National League for Nursing) calling for a radical paradigm shift in nursing curricula and transformation of current teaching methods rather than merely reorganization of subjects or adding more content into a saturated curriculum remains relevant today. The report also mentioned that many academics had had no formal input on how to teach adults and many educa- 
tors continue to teach the way they were taught. Early demands for change remain appropriate today; teacher centred-approaches may not prepare graduates for the ambiguities and uncertainties in healthcare systems that demands flexibility and an ability to think critically (National League for Nursing, 2003). Building a Problem-based Learning (PBL) approach into the curriculum has been mooted as a way to increase critical thinking and problem-solving abilities (Chang, Chang, Kuo, Yang, \& Chou, 2011; Conway \& McMillan, 2018).

There have been moves to introduce non-traditional modalities such as blended learning (Tokunaga, Yamaguchi, \& Yamamoto, 2017); simulation (Tamaki, et al., 2019); service learning (Glauberman, Mashino, \& Qureshi, 2019); and PBL (Itatani, Nagata, Yanagihara, \& Tabuchi, 2017) but these have been predominantly small-scale time-limited initiatives and there has been limited evaluation. To address concerns about the assessment of clinical skills there have been moves to introduce the Objective Structured Clinical Examination (OSCE) (Takishita, Iwasaki, Yamamoto, \& Matsuoka, 2017; Yamazaki, Kawata, \& Kawasaki, 2020) which is a valid and reliable tool for evaluating clinical competence in medical and nursing education. This is not widely used and assessment of clinical nursing skills remains a concern within the curriculum (Takishita, et al., 2017; Yamazaki, et al., 2020).

\section{Regulation of the curriculum}

Educational contents of the curriculum are regulated by the Public Health Nursing, Midwifery and Nursing School, and Training School by the Ministry of Health, Labour, and Welfare. Programs across nursing schools can differ but still meet these standards. The revision of designated rules for Public Health Nursing, Midwifery, and Nursing School and Training will be launched in April 2022. In 2016 the Committee for Fostering Human Resources in Nursing Education, within the Ministry of Education, Culture, Sports, Science, and Technology reviewed the core abilities for nursing practice within bachelor degree programs and achievement of goals at graduation. They found that "The model core curriculum for nursing science education" for BSN program and enumerated learning objectives within "The model core curriculum for nursing science education" should act as a reference point from which to construct curriculum in each university (Committee for Fostering Human Resources in Nursing Education, Ministry of Education, Culture, Sports, Science and Technology, 2017; Horinouchi, et al., 2018). The core set of competencies mentioned in the model specifies 5 groups of abilities necessary for nursing practice: One group "Basic nursing knowledge underlying nursing practice" incorporates profession- al knowledge and skills needed and includes implementation of the nursing process.

\section{Standards and the Nursing Process}

The Japanese Nursing Association publishes Standards of Nursing Practice which include responsibilities, contents, and measures in nursing practice, and apply to all public health nurses, midwives, nurses, and associate nurses regardless of workplace context (Japanese Nursing Association, 2016b). It focuses on judgment as a necessity for nursing practice based on professional knowledge and records a series of nursing processes.

Members of the nursing profession continuously observe individuals, families, groups, and communities needing nursing care; make comprehensive assessments based on clinical reasoning and judgment to plan, implement, and evaluate care. Nursing processes are documented in the patient's file to document nurses' judgments and actions. This record is used by the treating healthcare team and has a role in guiding care. The records have a vital role in the maintenance of continuity, consistency, quality improvement, and objectivity in nursing practice.

The nursing process provides a template for nurses to consider the need to collect data, plan care, implement care, and continuously evaluate each step of nursing care (Alfaro-LeFevre, 2010; Herdman \& Kamitsuru, 2017). It provides nurses with a 'helicopter view' of the overall approach to care. However, additional attention needs to be paid to the development of the necessary 'thought processes', that is those that focus on critical thinking, inquiry, reasoning and judgment and an ability to reflect on whether nursing actions have been 'therapeutic' (important to the patient and helpful in symptom management of their symptoms). This series of actions within a prescribed process is intended to enable nurses to respond quickly in dynamic situations and move flexibly when changes occur in people's health conditions and life circumstances. They can adjust support for better management of the environment and use various resources as necessary. Without a focus on the development of an inquiry process, the nursing process could lead to a 'transactional' approach that is not consistent with a professional level of care.

\section{Critical thinking, clinical reasoning, and clinical judgment}

Strategies to improve critical thinking skills, active learning, independent decision-making and problem-solving skills of Japanese students across all academic disciplines were promoted in the 2002 White Paper of the Japanese Education (Ministry of Education, Culture, Sports, Science and Technology, 2002). The new knowledge society demanded high levels of creativity, individuality, and analytical skills (Rear, 2012). 
There have been numerous attempts to define critical thinking, it relates to nursing because of its contribution to clinical competence (Chang, Chang, Kuo, Yang, \& Chou, 2011; Yildirum \& Ozkahraman, 2011) which is rooted in the ability to verify assumptions, interpret, analyze, evaluate and support reasoning (Paul, 2007). Facione, Facione, and Giancarlo (1994) developed the California Critical Thinking Disposition Inventory constructed from Openmindedness, Analyticity, Cognitive Maturity, Truth-seeking, Systematicity, Inquisitiveness, and Self-Confidence: Makimoto (1997) translated it into Japanese. Facione (2011) meanwhile, sought consensus (or perhaps compromise) from expert opinion to come up with the six broad categories - interpretation, analysis, evaluation, inference, explanation, and self-regulation. The Japanese scales measuring critical thinking orientation were developed by Hirooka, Ogawa, \& Motoyoshi (2000) with subscales of objectiveness, sincerity, and an 'inquiry-mind', and also by Hirayama \& Kusumi (2004) with subscales of awareness for logical thinking, 'inquiry-mind,' objectiveness, and evidence-based judgment. There are various definitions and rating scales developed in other countries or disciplines used for basic educational evaluation as well as for the definition of nursing judgment capacity in Japanese nursing research (Ogata, 2016). Ogata (2016) also identifies the challenges of teaching critical thinking and fostering clinical judgment in nursing practice.

Clinical reasoning and judgment are clinically applied examples of critical thinking and reasoning. Tanner (2006, p.208) defined the term "clinical reasoning" as the processes by which nurses make their judgments, and it includes both the deliberate process of generating alternatives, weighing them against the evidence, and choosing the most appropriate within those patterns. Also, "clinical judgment" refers to an interpretation or conclusion about a patient's needs, concerns, or health problems, and/or the decision to take action (or not), to use or modify standard approaches, or improvise with new ones as deemed appropriate by the patient's response. Reflection in action or reflection on action facilitates thinking and learning toward increased nursing competence (Schön, 1983). The nursing curricula, assessment, and teaching style all need to foster the development of critical thinking, clinical reasoning, and critical appraisal (Papathanasiou, Kleisiaris, Fradelos, Kakou, \& Kourkouta, 2014; Parkes, Hyde, Deeks, \& Milne, 2011). The same challenge about clinical reasoning and judgment exists in Japan as well, and a critical thinking scale has been used for evaluation in fundamental education or clinical nursing practice (Ogata, 2016).

\section{Clinical reasoning, the nursing process, and nursing diag- nosis}

A range of healthcare professionals collaborate to deliver care and each discipline has its own body of knowledge so a common understanding of therapeutic intent is essential to facilitate accurate communication. A NANDA-International Nursing diagnosis is "a clinical judgment concerning a human response to health conditions/life processes, or a vulnerability for that response, by an individual, family, group or community" (NANDA-International, 2020). It then guides the selection of nursing interventions to achieve outcomes for which the nurse has accountability (Herdman \& Kamitsuru, 2017).

A Japanese version of nursing diagnosis has been developed (Kuroe, et al., 2020). The NANDA-International nursing diagnosis was introduced and a Japanese research society of Nursing Diagnosis established in 1991. The society transitioned to the Japan Society of Nursing Diagnosis in 1995 to guide its use in Japan. The project reports by the Japan Society of Nursing Diagnosis indicated that the medical health records of more than half of medical institutions have introduced NANDA-International nursing diagnosis in Japan with regional variations (Egawa, Kuroda, Fukuda, \& Furukawa, 2016; Fukuda, et al., 2019) but only about approximately half of the educational institutions promote the nursing diagnosis as part of the nursing process (Egawa, Kuroda, Fukuda, \& Furukawa, 2016; Fukuda, et al., 2019). The nursing diagnosis expresses one set of common nursing terminologies, but momentum for the development of a Japanese-style nursing diagnosis that takes into account Japan's cultural soil, laws, and medical system has increased (Kuroe, et al., 2020).

The inclusion of clinical reasoning into the undergraduate nursing program was recently mandated by the Ministry of Education, Culture, Sports, Science, and Technology (Odajima \& Furuichi, 2020). A search of the Ichushi-Web hosted by the Japan Medical Abstract Society revealed that clinical reasoning in nursing is an increasingly popular research concern. Before 2010 there was no mention of this topic but since 2012, 197 papers as of September 2019 with keywords of "clinical reasoning" and "nursing" have appeared, including conference abstracts. Most of these have been commentaries and there are only 8 original research studies (Table 1).

\section{Challenges}

Ideology, tradition, and culture impact the development of effective clinical reasoning or nursing diagnosis model for nurses. Ideological reasons include the strongly patriarchal and hierarchical health system in which physicians traditionally make decisions for patients and have an authoritarian leadership style 
Table 1. Japanese nursing trends in clinical reasoning

\begin{tabular}{lccccc}
\hline year & Original paper & Review & Commentary & Conference abstracts & Others \\
\hline 2010 & 0 & 0 & 1 & 0 & 0 \\
2012 & 0 & 0 & 11 & 21 & 3 \\
2013 & 0 & 0 & 19 & 0 & 0 \\
2014 & 2 & 0 & 19 & 0 & 0 \\
2015 & 1 & 0 & 21 & 5 & 4 \\
2016 & 1 & 0 & 43 & 6 & 0 \\
2017 & 1 & 1 & 4 & 4 & 0 \\
2018 & 0 & 0 & 14 & 10 & 0 \\
2019 & 3 & 0 & 153 & 28 & 7 \\
Total & 8 & 1 & & \\
\hline
\end{tabular}

(Powell, 2006). The need to educate Japanese nurses as independent practitioners with a unique skillset rather than being subservient to their medical colleagues has been recognized (Primomo, 2000) but a strongly hierarchical patriarchal health system is resistant to change (Omura, Stone, \& Levett-Jones, 2018; Taylor Slingsby, Yamada, \& Akabayashi, 2006). Increased autonomy will require nurses to have well developed critical thinking skills.

Traditionally in Japan, there is a "very sharply defined ranking and status hierarchy" (Fujihara, 2020, p.551) as well as an occupation-based, seniority-based social status hierarchy: doctors and professors have high social standing (Fujihara, 2020), and nurses lower. This affects nurses' autonomy and opportunities for independent problem solving and decision making. Gender also plays a strong role in status differences between a predominantly male medical workforce and a predominantly female nursing workforce.

It has been argued that critical thinking is a culturally-based concept and is neither characteristic nor suited to people from Japan and Southeast Asia more widely (Atkinson, 1997). Atkinson argues that critical thinking fits uncomfortably with Japanese collectivist harmony-seeking culture. Many of Atkinson's arguments have been refuted: it is simplistic to think of Japanese society as mono-cultural; and the critical thinking process itself can be conducted in a collegial rather than confrontational way (Rear, 2012). There is an appreciation of the importance of the development of a skillset suited for today's society and there is a Japanese version of the 21st Century Competencies called "Ikiru-chikara (Zest for life)" that emphasizes the importance of logical critical thinking, problem-solving, metacognition, collaboration and self-direction (National Institute for Educational Policy Research, 2014). This has been introduced into Japanese primary and secondary education systems that precede entry to universities. Higher education for nursing should include perspectives and responses to educational and societal changes. Further devel- opment is needed.

\section{CONCLUSIONS}

The needs of health service consumers and patients and the context of health care have changed in Japan as they have elsewhere across the world. Paradigm shifts take time but there is evidence of many elements of professional practice and education that have changed globally. The context and culture of the academic environment have also changed evolutionarily over the last three decades. The need for more revolutionary change in nurse education arose as e-technologies became prominent in the academic workspace and the context of increasing clinical complexities. If the nursing process as a model for clinical nursing in Japan is to serve as a sound basis it needs to be underpinned by reflective practice and critical thinking. This requires that these processes are included in the nurse curriculum and faculty members need to achieve a full appreciation of the use of critical thinking, clinical reasoning, and clinical judgment within a process-oriented philosophy and methodology if they are to develop a level of comfort in encouraging this among their students. Clinical skills are part of a bigger therapeutic process. Teachers need to develop skills in causing students to 'think about what needs to be done for and with their patients. There needs to be a relationship between any nursing framework like the nursing process and the development of sound judgment and decision-making that leads to appropriate therapeutic actions.

Recently, the drastic change imposed on the health service and higher education sectors across the world because of the emergence of COVID 19, provides a chance to consider different educational strategy for approaching the necessary steps (Morin, 2020). In most instances, an evolutionary or revolutionary change agenda requires considerable professional development of all stakeholders in any processes of professional practice and 
curriculum renewal.

\section{REFERENCES}

Alfaro-LeFevre, R. (2010/2012). Applying Nursing Process: A tool for critical thinking 7th ed. (Hongo, K.Trans.). Tokyo: Igaku-shoin.

Alfaro-LeFevre, R. (2017). Critical thinking, clinical reasoning, and clinical judgment: A practical approach 6th edition, Philadelphia: Elsevier Inc.

American Nurses Association. (2015). Nursing: Scope and Standards of Practice, Third Edition. Washington, DC: American Nurses Publishing.

Arimoto, A., Gregg, M. F., Nagata, M., Miki, Y., \& and Murashima, S. (2012). Evaluation of doctoral nursing programs in Japan by faculty members and their educational and research activities. Nurse Education Today, 32, e1-e7). doi:10.1016/j.nedt.2011.06.007.

Atkinson, D. (1997). A critical approach to critical thinking in TESOL. TESOL Quarterly, 31(1), 71-94.

Baron, K. A. (2017). Changing to concept-based curricula: The process for nurse educators. The Open Nursing Journal, 11, 277. Chang, M. J., Chang, Y. J., Kuo, S. H., Yang, Y. H., \& Chou, F. H. (2011). Relationships between critical thinking ability and nursing competence in clinical nurses. Journal of Clinical Nursing, 20(21-22), 3224-3232.

Committee for Fostering Human Resources in Nursing Education, the Ministry of Education, Culture, Sports, Science and Technology, Japan. (2017). Model Core Curriculum for Nursing Education in Japan: Learning objectives aiming for acquiring "core abilities of nursing practice in the bachelor's degree program". Retrieved October 1, 2020, from https://www.mext.go.jp/content/20200428-mxt_igaku1217788_4.pdf.

Conway, J., \& Mcmillan, M. (2018). Critical Thinking and PBL: What, Why, and How? Journal of Problem-based Learning, 5(1), $1-4$.

Egawa, T., Kuroda, Y., Fukuda, K., \& Furukawa, H. (2016). A survey on nursing diagnosis use in Japanese medical institutions with more than 300 beds and educational situation using nursing diagnosis in Japanese basic nursing educational institutions. Journal of Japan Society of Nursing Diagnosis, 21(1), 29-39). (in Japanese).

Eniss, R H. (1985). A Logical Basis for Measuring Critical Thinking Skills. Educational Leadership, 43(2), 44-48.

Facione, P. A. (2011). Critical thinking: What it is and why it counts. In. Millbrae: The California Academic Press.

Facione, N.C., Facione, P.A., \& Sanchez, A.C. (1994). Critical thinking disposition as a measure of competent clinical judg- ment: The development of the California Critical Thinking Disposition Inventory. Journal of Nursing education, 33(8), 345350.

Fukuda, K., Furukawa, H., Kuroda, Y., Masuda, M., Miyagi, C., Kikuchi, M., \& Mikami, R. (2019). Realities of nursing diagnosis, outcomes, and interventions among medical and educational institutions. Journal of Japan Society of Nursing Diagnosis, 24(1), 32-39). (in Japanese).

Fujihara, S. (2020). Socio-economic standing and social status in contemporary Japan: Scale constructions and their applications. European Sociological Review, 36(4), 548-561.

Glauberman, G., Mashino, S., \& Qureshi, K. (2019). A pilot study to examine service-learning in disaster nursing education in Japan. Health Emergency and Disaster Nursing, 6(1), 35-42.

Herdman H.T. \& Kamitsuru S (Eds.). (2017). NANDA International Nursing Diagnoses: Definitions and Classification 20182020, Eleventh Edition. NANDA International, Inc. the Thieme Group. Stuttgart/New York.

Hirayama, R., \& Kusumi, T. (2004). Effect of Critical Thinking Disposition on Interpretation of Controversial Issues: Evaluating Evidences and Drawing Conclusions. Japanese Journal of Educational Psychology, 52, 189-198). (in Japanese).

Hirooka, S., Ogawa, K., \& Motoyoshi, T. (2000). An Exploratory Study of Measurement of "the Orientation toward Critical Thinking". Bulletin of the Faculty of Education Mie University (Education), 51, 161-173). (in Japanese).

Horinouchi, M., Okamura, C., Tanaka, H., Sadamura, M., Onishi, N., Sato, A., Tanaka, I., Kogusuri, Y., Takemasa, M., \& Saito, M. (2018). The process of curriculum revision for nursing education for human resource development that can promote Community based integrated care. Bulletin of Teikyo University of Science, 14, 191-197.

Ishibashi, A., Fukuyama, Y., Matsunaga, H., Noguchi, N., Tanaka, S., \& Shinchi, K. (2017a). A Survey on International Nursing Education of National Universities in Japan. Asian Journal of Human Services, 12, 8-16.

Ishibashi, M., Majima, T., Okada, S., Komiyama, M., Sakajo, A., Ishimaru, M., Nakai, A., Nogawa, K., Ozawa, H., \& Shimamura, A. (2017b). The improvements of the undergraduate nursing curriculum in Chiba University's School of Nursing. Reconstructing educational goals and establishing a curriculum that leads to improved student competency by graduation. Journal of Graduate School of Nursing, Chiba University, 39, 43-49). (in Japanese).

Itatani, T., Nagata, K., Yanagihara, K., \& Tabuchi, N. (2017). Content analysis of student essays after attending a problem-based learning course: Facilitating the development of critical thinking 
and communication skills in Japanese nursing students. Healthcare, 5(3), 47.

Japan Association of Nursing Programs in Universities (JANPU). (2020). The FY 2018 Fact-finding at Japan Association of Nursing Programs in Universities. Retrieved January 10, 2021, from https:// www.janpu.or.jp/wp/wp-content/uploads/2020/05/2019DB.pdf (in Japanese).

Japanese Nursing Association. (2016a). Nursing in Japan. Retrieved October 1, 2020, from https://www.nurse.or.jp/jna/english/ nursing/index.html (in Japanese).

Japanese Nursing Association. (2016b). The standard of nursing practice (Revised 2016). November 10, 2020, Retrieved from https:// www.nurse.or.jp/nursing/practice/kijyun/pdf/kijyun2016.pdf (in Japanese).

Japanese Nursing Association. (2015). Future Vision of Nursing: Nurses' endeavour toward 2025 - Nursing supports and sustains human life, living, and dignity-. Retrieved November 10, 2020, from https:// www.nurse.or.jp/home/about/vision/pdf/vision-4C.pdf (in Japanese).

Kuroe, Y., Egawa, T., Okutsu, A., Kodaira, K., Nishida, N., Hasegawa, T., Nin, K., \& Shimomai, K. (2020). A report on initiatives toward the building of the Japanese version of nursing diagnosis. Journal of Japan Society of Nursing Diagnosis, 25(1), 11-26). (in Japanese).

Kusumi, T. (2015). Critical thinking on education: Examination based on the nursing process. Journal of Japan Society of Nursing Diagnosis, 20(1), 33-38). (in Japanese).

Long, S. O. (1984). The sociocultural context of nursing in Japan. Culture, Medicine and Psychiatry, 8(2), 141-163.

Makimoto, K. (1999). Improvement of critical thinking disposition scale Japanese version. Proceedings of the Academic Conference, Japan Academy of Nursing, 19, 498-499). (in Japanese).

McGillis Hall, L., Lalonde, M., Kashin, J., Yoo, C., \& Moran, J. (2018). Changing nurse licensing examinations: media analysis and implications of the Canadian experience. International Nursing Review, 65, 13-23.

McMillan, M., \& Little, P. (2019). Learning outcomes for contemporary practice: Are we there yet? Journal of Problem-based Learning, 6(2), 45-46.

Miki, Y., Gregg, M. F., Arimoto, A., Nagata, M., \& Murashima, S. (2012). Evaluation of doctoral nursing programs by doctoral students in Japan: cross-sectional questionnaire survey. Japan Journal of Nursing Science, 9, 160-168.

Ministry of Education, Culture, Sports, Science, and Technology. (2002). "Japanese Government Policies in Education, Culture, Sports, Science, and Technology 2002." Retrieved October 1,
2020, from: http://www.mext.go.jp/b_menu/hakusho/html/ hpac200201/index.html.

Ministry of Education, Culture, Sports, Science, and Technology. (2019). Table 2 List of nurses and practical nurses training facilities and admission capacity by year. Retrieved October 1, 2020, from https://www.mext.go.jp/content/20200417-mxt_igaku-10000 1205_21.pdf.

Ministry of Health, Labour, and Welfare. Retrieved October 1, 2020, from https://www.mhlw.go.jp/english/.

Ministry of Health, Labour, and Welfare. (2016). Establishing 'the Community-based Integrated Care System'. Retrieved October 1, 2020, from https://www.mhlw.go.jp/english/policy/care-welfare/care-welfare-elderly/dl/establish_e.pdf.

Morin, K.H. (2020). Nursing education after COVID-19: Same or different? Journal of Clinical Nursing, 29, 3117-3119.

NANDA International. (2020) Glossary of Terms. Retrieved October 1, 2020, from https://nanda.org/nanda-i-resources/glossary-of-terms/.

National Institute for Educational Policy Research. (2014). Overview of "principle of curriculum organization towards comprehensive development of competencies," Report No. 7, Basic Research on Curriculum Organization. (in Japanese) Retrieved January 10, 2021, from https://www.nier.go.jp/05_kenkyu_sei$\mathrm{ka} /$ pdf_seika/h25/2_1_allb.pdf.

National League for Nursing. (2003). Innovation in nursing education: A call to reform. Retrieved October 1, 2020, from http:// www.nln.org/docs/default-source/about/archived-position-statements/innovation-in-nursing-education-a-call-to-reform-pdf.pdf?sfvrsn $=4$.

Nurjono, M., Shrestha, P., Ang, I.Y.H., Shiraz, F., Eh, K.H., Toh, S.E.S., \& Vrijhoef, H.J.M. (2020). Shifting care from hospital to community, a strategy to integrate care in Singapore: process evaluation of implementation fidelity. BMC Health Services Research, 20, 452. https: / doi.org/10.1186/s12913-020-05263-w. Odajima, Y., \& Furuichi, M. (2020). Development and validation of a chronic disease nursing education program for enhancing clinical reasoning ability in undergraduate nursing students. Nagoya Journal of Medical Sciences, 82, 399- 405.

Ogata, Y. (2016). Review of the Literature on Critical Thinking for Nursing Practice in Japan. Bulletin of Hokkaido Bunkyo University, 40, 1-14). (in Japanese).

Okura, M., \& Takizawa, H. (2018). Attitudes and values expected of public health nursing students at graduation: A delphi study. Nurse Education Today, 65, 116-122.

Omura, M., Stone, T. E., \& Levett-Jones, T. (2018). Cultural factors influencing Japanese nurses' assertive communication: Part 2 - hierarchy and power. Nursing \& Health Sciences, 20(3), 283 
-288 .

Papathanasiou, I. V., Kleisiaris, C. F., Fradelos, E. C., Kakou, K., \& Kourkouta, L. (2014). Critical thinking: the development of an essential skill for nursing students. Acta Informatica Medica, 22(4), 283-286). doi:10.5455/aim.2014.22.283-286.

Park, M.Y., Conway, J., \& McMillan, M. (2016). Enhancing critical thinking through simulation. Journal of Problem-based Learning, 3(1), 31-40.

Parkes, J., Hyde, C., Deeks, J., \& Milne, R. (2011). Teaching critical appraisal skills in health care setting. Cochrane Database of Systematic Reviews, 3. Retrieved from https://www.cochranelibrary.com/cdsr/doi/10.1002/14651858.CD001270.pub2/full.

Paul, R. (2007). Critical thinking in every domain of knowledge and belief. Paper presented at the 27th Annual International Conference on Critical Thinking, Berkeley. http://www.criticalthinking.org/pages/critical-thinking-in-every-domain-ofknowledge-and-belief/698.

Powell, T. (2006). Cultural context in medical ethics: lessons from Japan. Philosophy, Ethics, and Humanities in Medicine, 1(1), 4.

Primomo, J. (2000). Nursing around the world: Japan-preparing for the century of the elderly. Online Journal of Issues in Nursing, 5(2), 2.

Rear, D. (2012). The dilemma of 'critical thinking', conformism, and non-conformism in Japanese education policy. In T. Isles \& P. Matanle (Eds.), Researching twenty-first century Japan: New directions and approaches for the electronic age. Maryland: Lexington Books.

Schön, D. (1983). The Reflective Practitioner: How Professionals Think in Action. London: Temple Smith.

Takishita, Y., Iwasaki, Y., Yamamoto, Y., \& Matsuoka, T. (2017). Literature review of the current status of objective structured clinical examinations in continuing nursing education. Bulletin of School of Nursing Kyoto Prefectural University of Medicine, 27, 57-62). (in Japanese).
Tamaki, T., Inumaru, A., Yokoi, Y., Fujii, M., Tomita, M., Inoue, Y., Kido, M., Ohno, Y., \& Tsujikawa, M. (2019). The effectiveness of end-of-life care simulation in undergraduate nursing education: A randomized controlled trial. Nurse Education Today, 76, $1-7$.

Tanner, T.A. (2006). Thinking like a nurse: a research-based model of clinical judgment in nursing. Journal of Nursing Education, 45(6), 204-2011.

Taylor Slingsby, B., Yamada, S., \& Akabayashi, A. (2006). Four physician communication styles in routine Japanese outpatient medical encounters. Journal of General Internal Medicine, 21(10), 10571062.

Tokunaga, K., Yamaguchi, Y., \& Yamamoto, M. (2017). The evaluation of nursing students to nursing skill practices using the blended learning in Japan. International Journal of Learning and Teaching, 3(1).

Tsujimura, M., Ishigaki, K., Yamamoto-Mitani, N., Fujita, J., Katakura, N., Ogata, Y., Mochizuki, Y., Okamoto, Y., \& Shinohara, Y. (2016). Cultural characteristics of nursing practice in Japan. International Journal of Nursing Practice, 22(Suppl. 1), 56-64.

Turale, S., Ito, M., Murakami, K., \& Nakao, F. (2009). Nursing scholarship in Japan: development, facilitators, and barriers. Nursing and Health Sciences, 11(2), 166-173.

Yamazaki, M., Kawata, M., \& Kawasaki, C. (2020). Literature review of objective structured clinical examination (OSCE) performance in midwifery education: Agenda for OSCE implementation. The Journal of Kansai University of Social Welfare, 23, 59-66). (in Japanese).

Yildirum, B. \& Ozkahraman, S. (2011). Critical Thinking in Nursing Process and Education International Journal of Humanities and Social Science, 1(13). Retrieved October 1, 2020, from https://www.ijhssnet.com/journals/Vol_1_No_13_Special_ Issue_September_2011/34.pdf. 